\title{
Thoracic trident pigmentation in Drosophila melanogaster: latitudinal and altitudinal clines in Indian populations
}

\author{
AK Munjal ${ }^{1}$, D Karan ${ }^{1}$, P Gibert ${ }^{2}$, B Moreteau ${ }^{2}$, \\ R Parkash ${ }^{1}$, JR David ${ }^{2 *}$ \\ 1 Department of Biosciences, Maharshi Dayanand University, Rohtak 124001, India; \\ ${ }^{2}$ Laboratoire populations, génétique, évolution, Centre national de la recherche \\ scientifique, 91198 Gif-sur-Yvette, France
}

(Received 21 April 1997; accepted 18 July 1997)

\begin{abstract}
Summary - Wild populations of Drosophila melanogaster were collected along a latitudinal transect between Ernaculum $\left(10^{\circ}\right.$ latitude) and Jammu $\left(32.4^{\circ}\right)$. Altitudes were also highly variable, from sea level up to more than $2000 \mathrm{~m}$. The intensity of dark pigmentation on the thorax (trident) was estimated visually using four phenotypic classes, in flies grown at 17 and $25^{\circ} \mathrm{C}$. Significant clines of increasing pigmentation were observed according to latitude and altitude. A multiple regression technique permitted improvement of the relationship between pigmentation and geographic parameters, so that $93 \%$ of the pigmentation variations among populations could be predicted by knowing both the latitude and altitude of original populations. These data strongly suggest an adaptive response of thoracic pigmentation to physical factors of the environment, and especially to temperature.
\end{abstract}

temperature adaptation / latitude / altitude / multiple regression/ body pigmentation

Résumé - La pigmentation du trident thoracique chez Drosophila melanogaster : clines de latitude et d'altitude dans les populations indiennes. Des populations naturelles de Drosophila melanogaster ont été collectées selon un transect latitudinal compris entre Ernaculum $\left(10^{\circ}\right.$ de latitude) et Jammu $\left(32,4^{\circ}\right)$. Les altitudes étaient également très variables, allant du niveau de la mer jusqu'à plus de $2000 \mathrm{~m}$. L'intensité de la pigmentation sombre du thorax (trident) a été estimée visuellement en utilisant quatre classes phénotypiques, chez des mouches élevées à 17 et à $25^{\circ} \mathrm{C}$. Des clines de pigmentation significatifs ont été observés en fonction de la latitude et de l'altitude. L'utilisation d'une régression multiple a permis d'améliorer la relation existant entre

* Correspondence and reprints 
la pigmentation et les paramètres géographiques, de telle sorte que $93 \%$ des variations de pigmentation entre les populations peuvent être prédites en connaissant à la fois la latitude et l'altitude d'origine. Ces données suggèrent fortement une réponse adaptative de la pigmentation thoracique aux facteurs physiques de l'environnement, en particulier, la température.

adaptation à la température / latitude / altitude / régression multiple / pigmentation corporelle

\section{INTRODUCTION}

Any living species with a broad geographic range is likely to exhibit a correlated genetic variation across its spatial range (Dobzhansky, 1970; Mayr, 1970; Ford, 1975; Dobzhansky et al, 1977; Merrel, 1981). Such variation may occur as a consequence of isolation by distance, reduction of gene flow and genetic drift. From an evolutionary point of view, an interesting situation occurs when genetic variation correlates with biotic or abiotic conditions of the local environments.

Several Drosophila species exhibit such geographic variation. Drosophila melanogaster, which was long believed to be quite homogeneous over its range because of its domestic status, now turns out to be a most geographically variable species (Lemeunier et al, 1986; David and Capy, 1988). Practically all kinds of genetically determined traits, including DNA sequences, allozyme frequencies, chromosome arrangements, numerous morphometrical, physiological and behavioural traits, may exhibit geographic trends. The adaptive significance of such genetical changes is suggested or suspected when they occur in a regular manner according to some environmental gradient (eg, latitudinal clines) and also when similar, parallel trends are observed on different continents (David and Capy, 1988; Prevosti et al, 1988).

A dark pattern on the thorax, called the thoracic trident, was previously investigated in numerous world populations (David et al, 1985) and also in the sibling species $D$ simulans (Capy et al, 1988). In $D$ melanogaster, a latitudinal cline was observed between latitudes of $30^{\circ}$ and above, and this cline was confirmed in populations from various parts of the world, including Europe, North Africa, tropical Africa, Australia and America. Genetically darker populations were observed at higher latitudes, ie, in colder places. The adaptive interpretation of such a pattern is the thermal budget hypothesis (David et al, 1985; Capy et al, 1988; Gibert et al, 1996; Ottenheim et al, 1996): darker bodies will better absorb solar radiations, favouring flight and general activity in cold environments; this would be, on the other hand, a serious disadvantage in hot sunny places.

In the paper of David et al (1985), no population was analysed between 20 and $30^{\circ}$ of latitude, and no clinal pattern was observed below a latitude of $20^{\circ}$, corresponding to subtropical and tropical climates, although light and dark populations were simultaneously observed in these latitudes.

We have extended our knowledge of trident pigmentation distribution by collecting Indian $D$ melanogaster at various latitudes ranging between 10 and $32.4^{\circ}$. Altitudinal variations were also included in the present study. A highly significant latitudinal cline has been found, combined with an altitudinal one. These data support the adaptive significance of genetic changes in trident pigmentation even if the precise selective mechanisms still remain hypothetical. 


\section{MATERIAL AND METHODS}

In the present study 14 natural populations have been investigated (see table I and fig 1) along a latitudinal transect, from Ernaculum (10 latitude) up to Jammu $\left(32.4^{\circ}\right)$. Altitudes were comprised between sea level (Madras) and $2070 \mathrm{~m}$ (Manali).

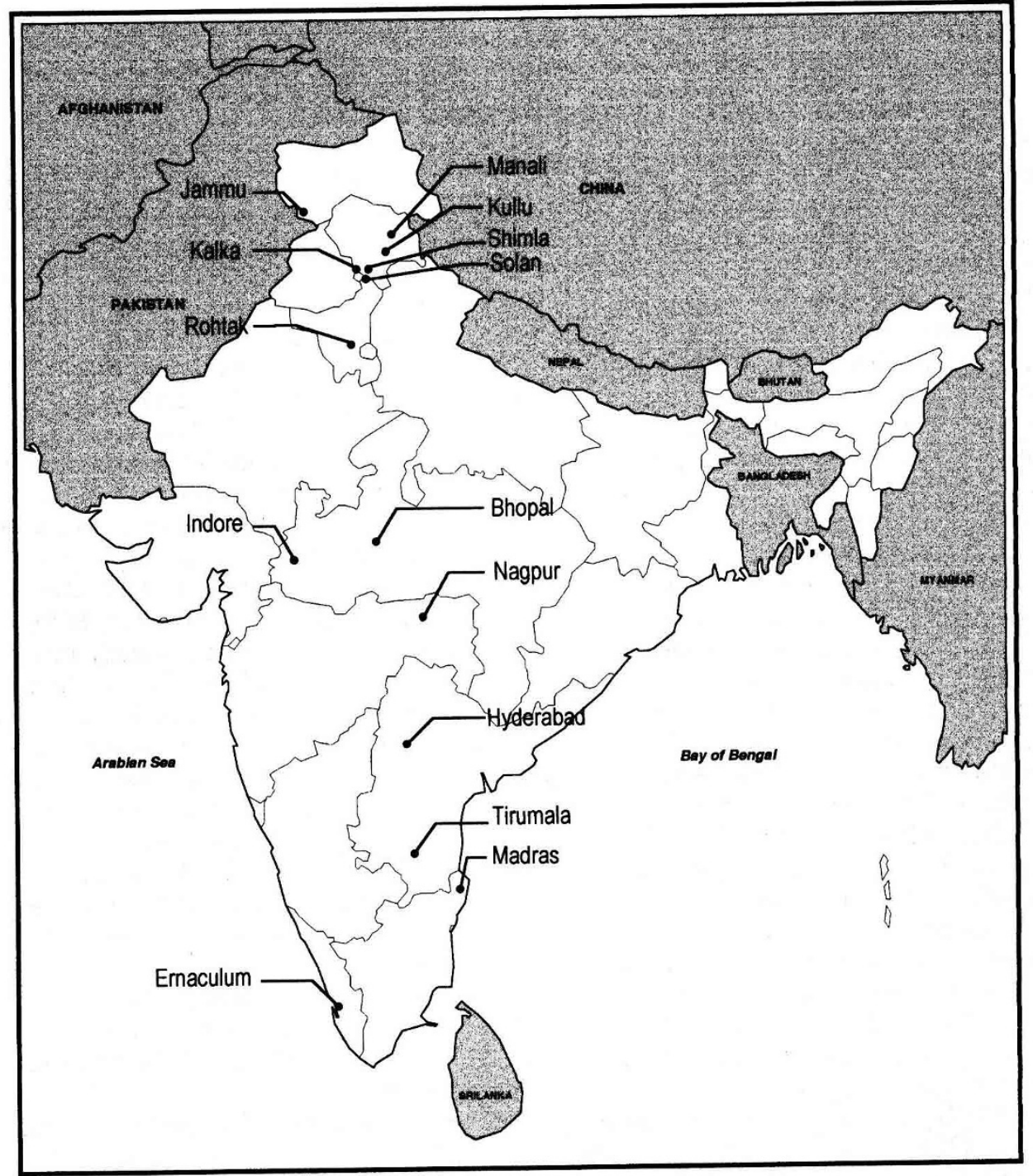

Fig 1. Map of India showing the localities from which natural populations of $D$ melanogaster were sampled. 
Table I. List of the 14 natural populations investigated, with latitude and altitude of origin. Pigmentation scores of the thoracic trident are given separately for sexes and growth temperature, and $n$ is the number of flies.

\begin{tabular}{|c|c|c|c|c|c|c|c|c|c|c|}
\hline \multirow[t]{3}{*}{ Population } & \multirow[t]{3}{*}{ Latitude } & \multirow[t]{3}{*}{ Altitude } & \multicolumn{4}{|c|}{$17^{\circ} \mathrm{C}$} & \multicolumn{4}{|c|}{$25^{\circ} \mathrm{C}$} \\
\hline & & & \multicolumn{2}{|c|}{ Females } & \multicolumn{2}{|c|}{ Males } & \multicolumn{2}{|c|}{ Females } & \multicolumn{2}{|c|}{ Males } \\
\hline & & & $n$ & mean & $n$ & mean & $n$ & mean & $n$ & mean \\
\hline Ernaculum & 10.0 & 78 & 190 & 0.363 & 120 & 0.375 & 190 & 0.189 & 190 & 0.168 \\
\hline Madras & 13.0 & 16 & 220 & 0.350 & 200 & 0.370 & 210 & 0.100 & 170 & 0.118 \\
\hline Tirumala & 13.4 & 598 & 230 & 0.365 & 190 & 0.284 & 180 & 0.200 & 180 & 0.178 \\
\hline Hyderabad & 17.3 & 544 & 240 & 0.392 & 210 & 0.391 & 220 & 0.218 & 220 & 0.250 \\
\hline Nagpur & 21.1 & 311 & 220 & 0.395 & 210 & 0.500 & 180 & 0.256 & 200 & 0.208 \\
\hline Indore & 22.4 & 567 & 210 & 0.409 & 220 & 0.391 & 190 & 0.237 & 210 & 0.243 \\
\hline Bhopal & 23.2 & 523 & 180 & 0.667 & 190 & 0.518 & 190 & 0.310 & 190 & 0.300 \\
\hline Rohtak & 28.9 & 253 & 210 & 0.614 & 210 & 0.624 & 200 & 0.475 & 210 & 0.490 \\
\hline Kalka & 30.5 & 600 & 230 & 0.848 & 300 & 0.967 & 160 & 0.515 & 220 & 0.573 \\
\hline Solan & 30.8 & 1250 & 270 & 0.937 & 330 & 0.927 & 170 & 0.610 & 170 & 0.676 \\
\hline Shimla & 31.3 & 2000 & 430 & 1.374 & 320 & 1.441 & 230 & 0.954 & 230 & 1.035 \\
\hline Kullu & 32.0 & 1310 & 260 & 0.961 & 330 & 0.988 & 290 & 0.614 & 270 & 0.650 \\
\hline Manali & 32.3 & 2070 & 330 & 1.442 & 270 & 1.333 & 240 & 1.029 & 200 & 1.015 \\
\hline Jammu & 32.4 & 366 & 220 & 0.964 & 200 & 0.930 & 210 & 0.552 & 210 & 0.486 \\
\hline
\end{tabular}

Wild living $D$ melanogaster adults were collected either by sweeping with a net or with banana traps, and taken back to the laboratory for establishing mass cultures. The specific identification was easy since the sibling species, $D$ simulans does not exist in India (Das et al, 1995). The number of founder females was generally comprised between 20 and 50. After two or three laboratory generations, experimental cultures with a low larval density were established both at 17 and $25^{\circ} \mathrm{C}$. For each population and temperature, several replicate cultures were generally established. A short egg laying period helped to control larval density. Preliminary observations showed that variations between cultures if any, were very slight, and no attempt was made to consider this factor. All the adults obtained at the same temperature for the same population were pooled and then scored for pigmentation intensity a few days later. As in a previous paper (David et al, 1985), flies were classified using four phenotypic classes, ranging from 0 (no trident) to 3 (dark trident), so that mean values may range between 0 and 3 . For each population and temperature, several hundred flies were scored. With only four phenotypic classes, the frequency distributions were often asymmetrical and skewed either to the left or to the right (fig 2 and David et al, 1985). For a general statistical analysis, we considered the frequencies of the four classes in a log-linear analysis of the contingency table (Sokal and Rohlf, 1995) using the Statistica software. For the regression analyses in relation to geographic gradients, we simply used the average pigmentation score of each population. 

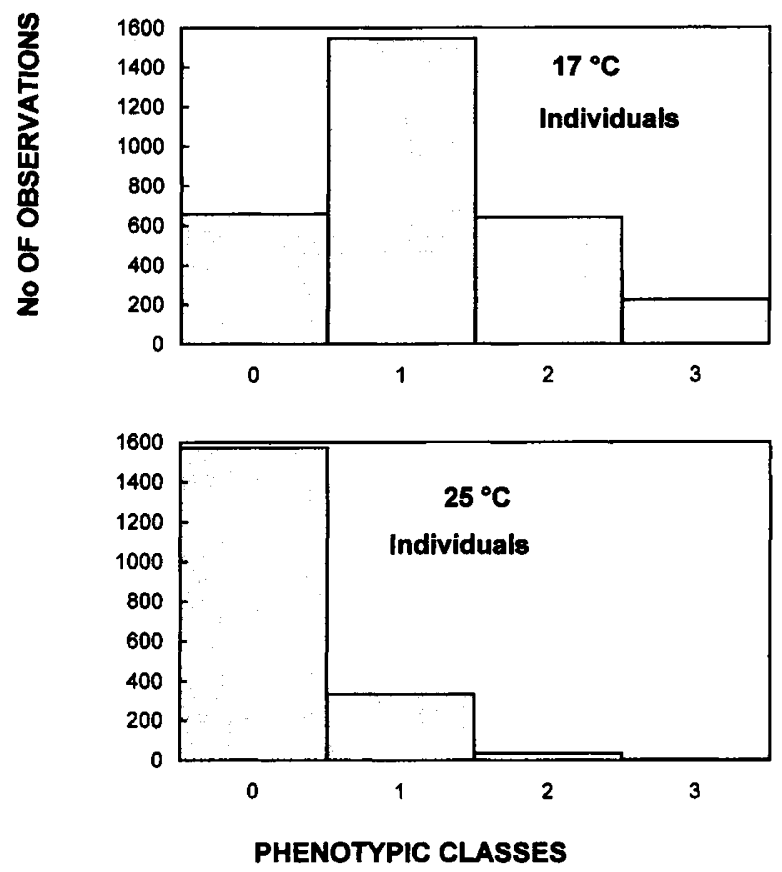

Fig 2. Examples of distribution frequencies of thoracic trident pigmentation in flies grown either at 17 or $25^{\circ} \mathrm{C}$. For each temperature data from five similar populations were pooled (Kalka, Kullu, Manali, Shimla and Solan for $17^{\circ} \mathrm{C}$; Ernaculum, Hyderabad, Indore, Nagpur and Tirumala for $25^{\circ} \mathrm{C}$ ). Mean pigmentation scores are: 1.14 and 0.22 , respectively.

\section{RESULTS}

The 14 populations investigated with their geographic characteristics are listed in table I, and also the basic data concerning average pigmentation in females and males.

\section{General analysis of the whole data set}

Results of the log-linear analysis are given in table II. All direct effects and possible interactions are highly significant, excepted for sex effect, one triple interaction (classes, temperatures and sex) and the quadruple interaction.

Significant differences are demonstrated between populations, and the major effect is observed in the 1-2 interaction (interaction between populations and different class frequencies, ie, different mean phenotypes). Interestingly, sex has a significant effect in double interactions, with class frequencies, populations and temperature, but all these effects remain quite small; the major conclusion is that, within each population, male and female are similar. In further investigations, a single average value will be taken for each population. 
Table II. Results of a log-linear analysis applied on phenotypic classes in the various populations. Effects of the main factors are shown, as well as all possible interactions. df: degrees of freedom.

\begin{tabular}{|c|c|c|c|}
\hline Source of variation & $d f$ & $\chi^{2}$ & Significance \\
\hline Classes (1) & 3 & 8722.86 & $* * *$ \\
\hline Populations (2) & 13 & 265.15 & $* * *$ \\
\hline Temperature $(3)$ & 1 & 131.82 & $* * *$ \\
\hline Sex (4) & 1 & 1.60 & ns \\
\hline $11^{*} 2$ & 39 & 2481.17 & $* * *$ \\
\hline $1^{*} 3$ & 3 & 771.74 & $* * *$ \\
\hline $1 * 4$ & 3 & 44.36 & $* * *$ \\
\hline $2 * 3$ & 13 & 75.53 & $* * *$ \\
\hline $2 * 4$ & 13 & 59.13 & $* * *$ \\
\hline $3 * 4$ & 1 & 20.17 & $* * *$ \\
\hline $1 * 2 * 3$ & 39 & 170.64 & $* * *$ \\
\hline $1 * 2 * 4$ & 39 & 50.61 & ns \\
\hline $1^{*} 3^{*} 4$ & 3 & 199.44 & $* * *$ \\
\hline $1 * 2 * 3 * 4$ & 39 & 25.77 & ns \\
\hline
\end{tabular}

Level of significance: ns, non-significant; ${ }^{* * *} P<0.001$.

\section{Variations of pigmentation according to latitude or altitude}

The significant variations between populations are further investigated by considering their relationship with geographic parameters. Regression coefficients in relation to latitude or altitude are given in table III, and in each case, significant variations are demonstrated in flies grown either at 17 or $25^{\circ} \mathrm{C}$. Regressions can be vizualised by using data in table I.

For latitudinal data, the regression obtained at $17^{\circ} \mathrm{C}$ is located above that for $25^{\circ} \mathrm{C}$. The intercepts are positive but not different from zero. The slopes are highly different from zero but not different between 17 and $25^{\circ} \mathrm{C}$. On average, pigmentation increases by 0.35 units for every $10^{\circ}$ of latitude. Latitude explains $\left(\mathrm{R}^{2}\right) 72$ and $81 \%$ of the total variability for flies grown at 17 or $25^{\circ} \mathrm{C}$, respectively.

It seemed interesting to compare Indian populations living under tropical and subtropical climates, to temperate populations (France) experiencing mild summers and cold winters. As shown in figure 3, the results of French populations are in consistent agreement with the Indian cline. Pooling French and Indian populations slightly modified the slopes with regression coefficients of $0.0524 \pm 0.0040$ at $17^{\circ} \mathrm{C}$ and $0.0211 \pm 0.0040$ at $25^{\circ} \mathrm{C}$. Compared to data of table III, the slope becomes steeper for development at $17^{\circ} \mathrm{C}$, but less steep at $25^{\circ} \mathrm{C}$. This could suggest that the reactivity of thorax pigmentation to growth temperature is not exactly the same in French and Indian populations. A precise comparison of the shape of the reaction norms remains to be undertaken.

In Indian populations, thoracic pigmentation increases also with altitude. In that case, intercepts are positive and slightly significant. Slopes are positive and highly different from zero, but the difference between 17 and $25^{\circ} \mathrm{C}$ is not significant. 
Table III. Statistical analyses of linear regression of pigmentation in relation with latitude or altitude of origin, and results of a multiple regression analysis (pigmentation as a simultaneous function of latitude and altitude).

\begin{tabular}{|c|c|c|c|c|}
\hline \multicolumn{5}{|c|}{ Linear regression } \\
\hline Altitude & $\begin{array}{l}17{ }^{\circ} \mathrm{C} \\
25{ }^{\circ} \mathrm{C}\end{array}$ & $\begin{array}{l}0.33 \pm 0.08^{* *} \\
0.15 \pm 0.06^{*}\end{array}$ & $\begin{array}{l}0.000494 \pm 0.000087^{* * *} \\
0.000403 \pm 0.000057^{* * *}\end{array}$ & $\begin{array}{l}0.87^{* * *} \\
0.83^{* * *}\end{array}$ \\
\hline Latitude & $\begin{array}{l}17{ }^{\circ} \mathrm{C} \\
25^{\circ} \mathrm{C}\end{array}$ & $\begin{array}{l}-0.28 \pm 0.17 \mathrm{~ns} \\
-0.28 \pm 0.15 \mathrm{~ns}\end{array}$ & $\begin{array}{l}0.0409 \pm 0.0066^{* * *} \\
0.0301 \pm 0.0058^{* * *}\end{array}$ & $\begin{array}{l}0.85^{* * *} \\
0.90^{* * *}\end{array}$ \\
\hline \multicolumn{5}{|c|}{ Multiple regression } \\
\hline & & $a$ & $b_{1}$ (latitude) & $b_{2}$ (altitude) \\
\hline & $\begin{array}{l}17^{\circ} \mathrm{C} \\
25^{\circ} \mathrm{C}\end{array}$ & $\begin{array}{l}-0.14 \pm 0.11 \mathrm{~ns} \\
-0.14 \pm 0.08 \mathrm{~ns}\end{array}$ & $\begin{array}{l}0.0259 \pm 0.0053^{* * *} \\
0.0158 \pm 0.0039^{* *}\end{array}$ & $\begin{array}{l}0.00029 \pm 0.00007^{* * *} \\
0.00028 \pm 0.00005^{* * *}\end{array}$ \\
\hline
\end{tabular}

Level of significance: ns, non-significant; ${ }^{*} P<0.05 ;{ }^{* *} P<0.01$; $^{* * *} P<0.001$.

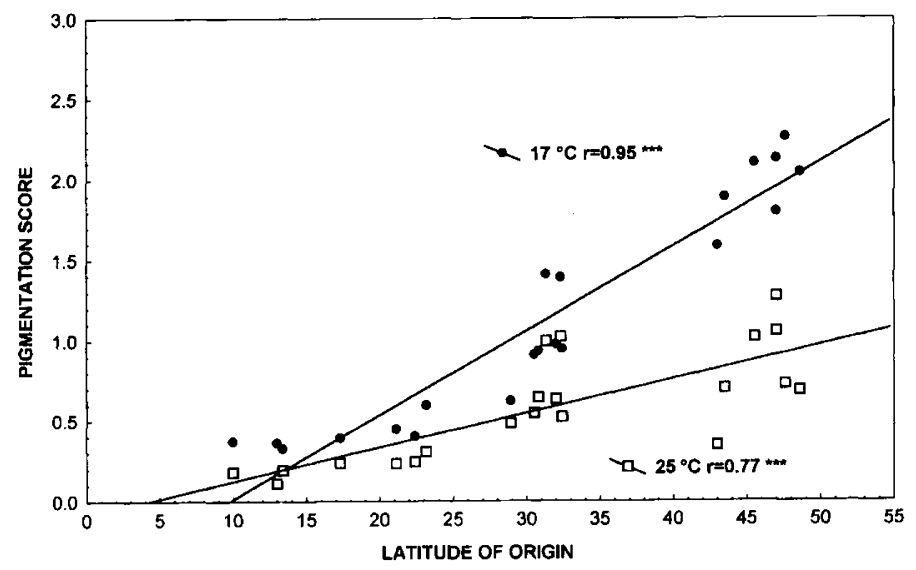

Fig 3. Relationship between latitude of origin and pigmentation of thoracic trident for flies grown at 17 and $25^{\circ} \mathrm{C}$. Values below $35^{\circ}$ of latitude correspond to Indian populations; above $40^{\circ}$ to French populations taken from David et al (1985).

On average, pigmentation increases by 0.45 units per $1000 \mathrm{~m}$. Altitude by itself explains between 69 and $76 \%$ of the total variation.

The latitude and altitude of origin of the Indian populations are not independent. Table I shows that the darkest populations were collected both at high latitudes and at high altitudes. The correlation between altitude and latitude is, however, not very high $(r=0.63)$, and the two geographic characteristics are partly independent. For 
that reason, we analysed the data with the multiple regression technique, according to the formula:

$$
\text { pigmentation }=a+b_{1} \text { latitude }+b_{2} \text { altitude }
$$

Values of the coefficients are given in table III. The intercepts are negative but not significantly different from zero. On the other hand, the $b_{1}$ and $b_{2}$ parameters are always highly significant. The weight which is attributed to $1^{\circ}$ of latitude is of course much more than the weight for $1 \mathrm{~m}$ in altitude. According to the coefficients, a latitudinal degree is equivalent to $88 \mathrm{~m}$ at $17^{\circ} \mathrm{C}$ and to $57 \mathrm{~m}$ at $25^{\circ} \mathrm{C}$.

Using the multiple regression, a predicted phenotypic value is calculated for each population, and an excellent concordance is observed between calculated and observed data $\left(r=0.96\right.$ at each temperature). About $93 \%\left(\mathrm{R}^{2}\right)$ of the variability that is found in nature can be predicted by the multiple regression. This is much more than the average $\mathrm{R}^{2}(0.74)$ obtained by considering separately either altitude or latitude. We may therefore conclude that the multiple regression technique considerably improved the relationship between geography and the genetic characteristics of natural populations.

\section{DISCUSSION AND CONCLUSIONS}

Thoracic trident pigmentation is a trait difficult to investigate for two reasons. First, phenotypic classes are made visually and may be subject to individual appreciation. In a previous paper (David et al, 1985) it was shown that, after some training, two independent observers would produce almost identical data on the same population. In the present work, observations in India were performed by Indian investigators, but training was provided by an author of the previous paper. Mean values of pigmentation scores can be compared not only among Indian populations, but also with previously published data. The second difficulty arises from the fact that, with only four classes, frequency distributions are far from normality and variance is highly dependent on mean. This difficulty could be overcome by considering the frequencies of the phenotypic classes in a log-linear analysis of the contingency table.

Results on Indian populations confirmed the latitudinal cline already observed in the same species in other parts of the world (David et al, 1985). The adaptive significance of thorax pigmentation variations is thus strongly supported. There are, however, some differences which deserve discussion.

The Indian cline has been found between latitudes of 10 and $32^{\circ}$, ie, an interval where no clinal trend was previously observed (David et al, 1985). At least two kinds of interpretations may be provided for this discrepancy. This might be due to some specific characteristics of the Indian climate. A second, completely different interpretation, concerns some possible bias in the previous paper (David et al, 1985). Numerous tropical and subtropical populations were investigated, but many of them had been kept for several years at $18^{\circ} \mathrm{C}$ as laboratory mass cultures. It may be possible that, because of genetic drift or of laboratory adaptation, some of these populations increased their pigmentation score, preventing the demonstration of a 
clear latitudinal effect. In favour of that interpretation, we may indicate that, since 1985, several tropical African or Caribbean tropical populations have been again investigated immediately after their collection and in no case was a dark trident observed.

An original observation on Indian populations is the altitudinal cline. In our sample, latitude and altitude were slightly correlated, since elevated localities were mostly found in the northern part of India, on the Himalayan foot hills. It seems, however, that altitude has a specific effect evidenced by the results of the multiple regression analysis. When both geographic criteria are combined, more than $90 \%$ of the genetic variability of trident pigmentation is explained.

Latitudinal and altitudinal variations are a powerful argument for assuming the adaptive significance of a cline, as a consequence of selection imposed by the environment. These ecological observations raise two main questions: what is the environmental factor responsible and what is the physiological target at the fly's level?

A classical functional interpretation of pigmentation variation is the thermal budget hypothesis (see Introduction). Under cold conditions, a dark body favoring the absorption of light radiation will provide a higher metabolic activity and will provide a better fitness. Conversely, under warm conditions, a dark pigmentation would lead to overheating and would be counterselected. Interestingly, adaptive pigmentation changes may occur either as a consequence of genetic changes (De Jong et al, 1996) or as a consequence of phenotypic plasticity (David et al, 1990; Gibert et al, 1996; Das et al, 1994). Alternative physiological processes may also be involved in adaptation. For example, a relationship could exist between darkening of the cuticle and tolerance to desiccation (David et al, 1983) or protection against UV rays.

Altitude is strongly correlated with average year temperature, while latitude is not, at least in India. In Rohtak, near Delhi (altitude $250 \mathrm{~m}$ ) the year average is $25.3{ }^{\circ} \mathrm{C}$, not very different from values in southern localities such as Ernaculum $\left(27.1^{\circ} \mathrm{C}\right.$ ) or Madras $\left(28.6^{\circ} \mathrm{C}\right)$. In Shimla (altitude $2000 \mathrm{~m}$ ) on the other hand, the year average is much less $\left(13.6^{\circ} \mathrm{C}\right)$ and the mean of the hottest month (June) does not exceed $20^{\circ} \mathrm{C}$. In such a place, there is no risk of overheating, and selection should favor cold adaptation. As stated above, the mean year temperature cannot be taken into account for explaining latitudinal variations, and seasonal variations must be considered. In India, a regular latitudinal trend exists for increasing the seasonal amplitude. Between month variation is very restricted in the south and humidity remains high all year round. By contrast, the winter temperature in Delhi is $15.6{ }^{\circ} \mathrm{C}$, while the Summer average is $33.0^{\circ} \mathrm{C}$. Thus, cold and heat selection are likely to occur on successive generations of the year. The fact that natural populations in the vicinity of Delhi are genetically darker than populations in Ernaculum suggests that cold adaptation might be more powerful than heat selection. But again we are not sure that ambient temperature is the only selective factor. 


\section{ACKNOWLEDGMENT}

This work was supported by the Indo-French Center for the Promotion of Advanced Research (IFCPAR, Contract 1103.1).

\section{REFERENCES}

Capy P, David JR, Robertson A (1988) Thoracic trident pigmentation in natural populations of Drosophila simulans: a comparison with $D$ melanogaster. Heredity $61,263-268$

Das A, Mohanty S, Parida BB (1994) Abdominal pigmentation and growth temperature in Indian Drosophila melanogaster: evidence for genotype-environment interaction. $J$ Biosci 19, 267-275

Das A, Mohanty S, Capy P, David JR (1995) Mating propensity of Indian Drosophila melanogaster with $D$ simulans: a nonadaptive latitudinal cline. Heredity $74,562-566$

David JR, Capy P (1988) Genetic variation of Drosophila melanogaster natural populations. Trends Genet 4, 106-111

David JR, Allemand R, Van Herrewege J, Cohet Y (1983) Ecophysiology: abiotic factors. In: Genetics and Biology of Drosophila (M Ashburner, HL Carson, JN Thompson, eds), vol 3d, Academic Press, New York, 105-170

David JR, Capy P, Payant V, Tsakas S (1985) Thoracic trident pigmentation in Drosophila melanogaster: differentiation of geographical populations. Genet Sel Evol $17,211-224$

De Jong PW, Gussekloo SWS, Brakefield PM (1996) Differences in thermal balance, body temperature and activity between non-melanic and melanic two spot ladybird beetles (Adalia bipunctata) under controlled conditions. J Exp Biol 199, 2655-2666.

Dobzhansky T (1970) Genetics of the Evolutionary Process. Columbia Univ Press, New York

Dobzhansky T, Ayala FJ, Stebbins GL, Valentine JW (1977) Evolution. WH Freeman and Co, San Francisco

Ford EB (1975) Ecological Genetics. Chapman and Hall, London

Gibert P, Moreteau B, Moreteau JC, David JR (1996) Growth temperature and adult pigmentation in two Drosophila sibling species: an adaptive convergence of reaction norms in sympatric populations? Evolution 50, 2346-2353

Lemeunier F, David JR, Tsacas L, Ashburner M (1986) The melanogaster species group. In: The Genetics and Biology of Drosophila (M Ashburner, HL Carson, JN Thompson, eds), Academic Press, New York, Vol 3E, 147-256

Mayr E (1970) Population, Species and Evolution. Harvard Univ Press, Cambridge

Merrel DJ (1981) Ecological Genetics. Longman, London

Ottenheim MM, Volmer AD, Holloway GJ (1996) The genetics of phenotypic plasticity in adult abdominal colour pattern of Eristalis arbustorum (Diptera: Syrphidae). Heredity 77, 493-499

Prevosti A, Ribo G, Serra L, Aguade M, Balana J, Monclus M, Mestres F (1988) Colonization of America by Drosophila subobscura: experiment in natural populations that supports the adaptive role of chromosomal inversion polymorphism. Proc Natl Acad Sci USA 85, 5597-5600

Sokal RR, Rohlf FJ (1995) Biometry. Freeman and Company, New York 